\title{
Challenges and Possibilities of Scaffolding Critical Reflection and Cultural Responsiveness for Pre-Service Special Educators
}

\author{
Bindiya Hassaram \\ Learning Differently \\ Phyllis M. Robertson \\ Texas A\&M University - Corpus Christi \\ Shernaz B. García \\ University of Texas at Austin
}

\begin{abstract}
Given the nature of their responsibilities in field-based settings, university supervisors play an important role in preparing pre-service teachers to become culturally responsive and critically reflective special educators. However, supervisors themselves may not have the experience and training necessary to do so, and limited guidance is available regarding effective mentorship practices to foster implementation of culturally and linguistically responsive pedagogy (CLRP) and critical reflection. This exploratory qualitative study examined how three supervisors engaged in post-observation conferences with their student teachers to promote critical reflection about CLRP using content and discourses analyses. Findings indicated that, although student teachers engaged in discussions about CLRP and were able to critically self-reflect, supervisors were unable to facilitate critical reflection vis-à-vis institutional practices and systemic bias. Theoretical and practical implications for supervision of practicum experiences in pre-service teacher education programs are offered.
\end{abstract}

Although essential in the education of pre-service teachers (PSTs), the role of the university supervisor has been largely unexamined in recent research. Typically, supervisors observe and then reflect with PSTs, guiding their thinking about instruction and its impact. Such supervisory conversations provide opportunities to discover how PSTs think (Holland, 1989; Zeichner \& Liston, 1985) and how supervisors actively cultivate the level and types of thinking in which they engage. 
Although supervisors contribute to the formal evaluation of PSTs to ensure compliance with preparation program requirements, their primary purpose is to provide a platform for PSTs to talk about pedagogical practices, reflect on beliefs, knowledge, and past actions, and engage in problem-solving through an iterative process of observation and feedback (Chamberlin, 2000; Zeichner \& Liston, 1987). Reflective practice (Schön, 1987) is the act of thinking back on an experience, evaluating it, generating possible solutions, and testing the solutions in practice. In education, it involves a teacher creating an active dialogue between theory and practice (Weshah, 2007) by studying his or her own teaching methods, curricula, students, and classroom environment, to determine what works best for students.

Cultivating reflective practice requires PSTs and supervisors to build an interpersonal relationship based on trust, support, effective communication, and shared goals (Goldhammer, 1969; Richardson-Koehler, 1988). PSTs co-construct knowledge actively and collaboratively with their supervisors, whose objective is to create the optimal conditions for reflection. Fostering this relationship and achieving desired outcomes requires considerable knowledge and skill on the part of supervisors. However, there is limited research available on best practices for supervisor preparation and practice and often, supervisors have limited preparation for the critical role they play (Bates, Ramires, \& Drits, 2009; Cuenca, 2010; Zeichner, 2005).

\section{Critical Reflection}

Critical reflection has been posited as a measure of PST's thinking about the practice of teaching beyond the classroom walls and to its wider sociopolitical impact (Hatton \& Smith, 1995). In order to effectively and equitably teach in today's increasingly diverse schools and society, critical reflection of curricula, teaching, and students is essential (Jacobs, 2006). Teacher education programs should support PSTs in developing an inquiry- and data-based approach to critical reflection, problem solving, and decision-making. In the field, supervisors can provide the scaffolds needed for PSTs to become critically self-reflective and transformative practitioners by providing opportunities for reflective practice, building trusting relationships, modeling critical reflection, and engaging PSTs using think-alouds and discourse to identify and reframe problems of practice (Achinstein \& Barrett, 2004; Bates et al., 2009; Bean \& Stevens, 2002). Such experiences provide a forum in which PSTs can learn how to "apply, reflect on, and refine their practice within a supportive environment of continuous, focused, professional dialogue" (Little \& Robinson, 1997, p. 434).

Extant literature indicates that PSTs should engage in critical self-reflection first, through examining their own teaching and classroom, before moving to critical reflection of school and society (Jacobs, 2006). While research on critical reflection in teaching is extensive, little is known about how to cultivate this broader level of critical reflection in beginning teachers (Bates et al., 2009). In order to consider the moral and ethical aspects of social justice in addition to the technical aspects of teaching, PSTs and their supervisors must first have the knowledge, skills, and understanding to practice culturally and linguistically responsive pedagogy (CLRP). 


\section{Culturally and Linguistically Responsive Pedagogy (CLRP)}

For supervisors and PSTs, lack of exposure, familiarity, and opportunity to interact with people from diverse groups (Cochran-Smith, Davis, \& Fries, 2004; Seidl, 2007) can result in cultural conflict (Marxen \& Rudney, 1999), as predominantly white educators bring their unexamined assumptions to teacher preparation programs (Sleeter, 2008) and classrooms. Differences in attitudes, values, beliefs, and traditions can also contribute to low expectations and deficit thinking (Valencia, 2010). Deconstructing these influences requires that supervisors themselves be knowledgeable regarding CLRP and critical reflection, so that they can model CLRP for their PSTs.

CLRP is "based on the assumption that when academic knowledge and skills are situated within the lived experiences and frame of reference of students, they are more personally meaningful, have a higher interest appeal, and are learned more easily and thoroughly" (Gay, 2000, p. 106). Responsive teachers understand that culture and language shape the thinking processes of groups and individuals, with both culture and language strongly influencing the attitudes, values, and behaviors that students and teachers bring to the instructional process (Gay, 2002). CLRP involves building on students' cultural and linguistic capital by using student-centered instructional methods, building connections between students' homes and school, and using intercultural communication and multicultural resources in instruction (Gay, 2002; Villegas \& Lucas, 2002).

\section{CLRP in Special Education}

Special education has long been recognized as part of the outcome of the larger systematic failure of schools to recognize the ways in which cultural diversity, such as ethnic, linguistic, and socioeconomic class-based diversity, influence different ways of being and knowing in children. (Seidl \& Pugach, 2009, p. 58)

To avoid such consequences, special educators must understand the intersectional nature of culture, language, and disability (García \& Ortiz, 2013) to implement CLRP and meet the needs of students with disabilities from culturally and linguistically diverse communities (Orosco \& O'Connor, 2014).

Teacher education programs must therefore provide opportunities for PSTs to build cultural self-awareness (Abt-Perkins, Hauschildt \& Dale, 2000), as well as to practice the principles of CLRP in special education. This includes (a) considering principles of language development in assessment, instruction, referrals and IEP development (García \& Ortiz, 2008; Harry \& Klingner, 2014; Linan-Thompson \& Ortiz, 2009; Orosco \& O'Connor, 2014); (b) using research-based linguistically responsive strategies such as peer collaboration, using language for communicative and authentic purposes, teaching literacy in students' dominant languages, and teaching vocabulary in explicit ways (Hoover, Klinger, Baca \& Patton, 2008; Orosco \& O'Connor, 2014); (c) providing instruction that maximizes students' funds of knowledge, using culturally diverse 
materials, and finding a balance between holistic and explicit instruction that helps students access prior knowledge, make connections, and build new knowledge (Amanti, 2005; Cloud, 2002; Hoover et al., 2008); and (d) seeking an understanding of families' belief systems around disability in order to involve parents in decision-making about the education of their children (Kalyanpur \& Harry, 2012; Kozleski \& Waitoller, 2010). Many teacher education programs purport to follow the guidelines provided by the Council for Exceptional Children (CEC; 2009) related to knowledge and skills standards for multicultural competence in special education in an effort to ensure their candidates are adequately prepared to provide equitable services.

\section{Supervision for Equity}

The study of supervision to foster CLRP and equity is minimal in both special education and general education. In a unique review of literature on culturally responsive supervision, Jacobs (2006) found only nine articles published between 1982 and 2003 that related supervision to issues of equitable teaching. Her review revealed that while critical reflection is an essential component of equitable teaching, PSTs may not have the experience to engage in critical reflection unless supervised by someone who can model this way of thinking. Jacobs (2006) concluded by stating that more empirical studies are needed to investigate the outcomes of this type of supervision on views and actions of PSTs as well as on their students' learning.

Researchers have advocated that universities should provide supervisors with professional development in order to increase their cultural responsiveness (Jacobs, 2006; Zozakiewicz, 2010). Abt-Perkins et al. (2000) suggest that supervisors should be prepared to guide PSTs to "shape their own problems in their own classroom contexts along "cultural dimensions"' (p. 45); that is, to question their practices from the perspective of race, ethnicity, gender, beliefs and assumptions about teaching and learning. Although there have been some efforts to infuse cultural responsiveness in special education preparation programs (e.g. Robertson, García, McFarland \& Rieth, 2012; Robertson, García \& Rodriguez, 2016; Sobel, Gutierrez, Zion, \& Blanchett, 2011) and provide professional development for special education faculty (e.g. Prater \& Deveraux, 2009), these efforts have not addressed the critical role of university supervisors in bridging university classroom theory to actual classroom practice.

A closer look at supervision conferences. Supervision conferences, typically conducted immediately after observation of a lesson delivered by the PST, provide a source of data from which the nature of supervisory conversations can be gleaned. Discourse analytic methods have been recommended as a tool with which to examine these interactions (Holland, 1989; Zeichner \& Liston, 1987). Very few studies have been conducted to examine PST's thinking about pedagogy during the process, and much of the existing research was conducted in the 1980s and 1990s. Zeichner and Liston's (1985) analysis of 26 supervision conferences revealed that most PST reflection discourse occurred at the factual level-where PSTs provided facts about their lessons; less than one percent of teachers' thinking revealed in supervision conferences was at the critical level. Zeichner and Liston (1985) hypothesized that PSTs may have a stronger influence on the level of conversation than the university supervisor with supervisors being unable to 
promote more complex modes of reasoning. In a follow-up study, Zeichner, Liston, Mahlios and Gomez (1988) compared the discourse of PSTs enrolled in preparation programs with two very different philosophies; one emphasized the technical aspects of teaching, while the other utilized an inquiry-oriented approach. In the latter, "student teachers [were] encouraged to reflect and examine the most effective and efficient means, to question the underlying assumptions embedded in educational practices, and to deliberate over the ethical aspects of teaching and educational institutions" (Zeichner et al., 1988, p. 351). Despite program differences, course requirements and program structure were the same. Discourse analysis revealed no significant differences in the type of thinking student teachers engaged in vis-à-vis program type. While the inquiry-oriented program actively engaged PSTs in reflective thinking, such thinking was not frequently reflected in post-observation conversations. The researchers posited that neither the inquiry-oriented program philosophy nor the professional development provided to supervisors about reflective supervision was successful in yielding evidence of critical thinking from PSTs.

Hatton and Smith (1995) derived five levels of reflection from their analysis of student teacher written reflections:

Level 1-Technical: Reporting events and focusing on the immediate, with no attempt to provide reason/justification;

Level 2-Descriptive: Providing reasons for actions and looking for 'best practices' based on personal judgment, based on analyzing areas for growth and development. Understanding that alternative reasons/perspective exist (e.g., I chose...because).

Level 3-Dialogic: Deliberate cognitive discourse within one's self that includes weighing different viewpoints and exploring alternatives. Stepping back and reflecting on possible alternatives (e.g., there may be several reasons the student did not respond to this...)

Level 4-Critical: Thinking about the effects of one's actions on others, taking the broader historical, social, and/or political context into account, and making practice problematic (e.g., the student management in this classroom is reflective of the power relationships between students and teachers in wider society).

Level 5-Contextual, Reflection in Action: Involves being able to apply Levels 1-4 as new situations arise.

Following a review of 16 studies about student teacher reflection, Hatton and Smith (1995) found "little evidence of critical reflection on the part of students, most of whom demonstrate the technical and practical types" (p. 38). While student teachers engaged in constructive criticism of themselves, with a view to improve and transform of their own practice (Bates et al., 2009; Cochran-Smith et al., 2004; Larrivee, 2000), they did not critically reflect on schooling in a broader sociocultural context.

Although many programs purport to emphasize the cultivation of reflective teaching practice, little is known about how this is successfully achieved. Common strategies include: (a) 
action research projects; (b) case studies, ethnographic studies, and examination of multiple perspectives; (c) microteaching, supervised practicum experiences, and critical dialogue; and (d) structured curriculum tasks, such as reading fiction and non-fiction, conducting oral interviews, writing journals, narratives, biographies, or reflective essays (Hatton \& Smith, 1995; SparksLanger \& Colton, 1991; Weshah, 2007), but there is little evidence of their effectiveness. In the rationale for a research study, Bates et al. (2009) report that in the past and currently, there is unwavering agreement on the "need of systematic and regular reflective practices" (p. 91). They conclude from their study that "supervisors who not only model critical [self-] reflection but also specifically, outwardly articulate the process are able to fully demystify critical reflection for their students" (Bates et al., 2009, p. 108).

\section{Rationale and Purpose}

In summary, although supervision has been recommended as a tool for fostering critical reflection (Hatton \& Smith, 1995; Sparks-Langer \& Colton, 1991; Weshah, 2007), few studies have explored how supervisors cultivate critical reflection, investigated what form reflection can and should take, or how reflection affects teachers' beliefs and practices (Bates et al., 2009; Bean $\&$ Stevens, 2002). Additionally, although there is a body of knowledge about the principles of university supervision, predominantly in general education, there is limited knowledge about supervision to foster CLRP and critical reflection in either general or special education.

The purpose of this study was to examine the dialogue exchanged during supervision conferences to reveal special education PSTs thinking about CLRP in their student teaching classrooms. The question guiding this research was: how do supervisory conversations promote student teacher critical reflection about CLRP? The findings are part of a broader study (Hassaram, 2013) which also explored contextual factors that appear to influence the nature and quality of discussions about CLRP in supervisory conversations.

\section{Method}

This exploratory qualitative study was conducted at a Southwestern American university, in an undergraduate special education program committed to teaching the theory and practice of CLRP. An interpretivist framework was used to capture the richness and complexity of phenomena as they occur in their naturalistic setting (Denzin \& Lincoln, 2005).

\section{Context}

Supported by funding from the Office of Special Education Programs, program faculty were working to develop, evaluate and institutionalize a restructured and improved undergraduate program to prepare special educators for CLRP (for a comprehensive overview see Robertson et al., 2012). To better understand the realignment efforts, the first author, a doctoral student in multicultural special education at the time, began to attend project meetings. She soon realized that 
the research on supervision practices to scaffold CLRP for PSTs was scant, and decided to pursue this in her research.

Participating undergraduates engaged in a five-semester program of study. During the first semester, they enrolled in four foundations courses including a field experience course in which they completed extensive observations in six special education settings. Extensive field experiences in a variety of special education settings continued to be an emphasis for the remainder of their program. They were supervised by university supervisors and received formative and summative evaluations every semester. During their final semester, student teachers (STs) spent 40 hours per week in a special education setting while simultaneously enrolled in a course on Intercultural Communication and Collaboration with the emphasized expectation of implementing CLRP in their classrooms.

\section{Participants}

Three university supervisors (two female, one male) of STs served as primary participants. Michelle (all names are pseudonyms) who identified as female, white, and Czech/English/Scottish, was pursuing a Ph.D. in special education administration, while seeking principalship certification. She expected to see improvement, learning, and growth in her STs and she expected open communication. Missy identified as female, white, and Portuguese, and was pursuing a doctorate in learning disabilities/behaviour disorders. She expected STs to be almost-beginning teachers, able to handle all aspects of the classroom, and deliver fluid lessons. She also valued open communication. Finally, Edwin identified as male, white, Irish American and Roman Catholic. Edwin was a doctoral student studying multicultural special education and expected his STs to be professional and independently execute all parts of their lessons.

Five STs (all female) served as secondary participants. Stephanie, who identified as EuroAmerican, grew up in a suburban neighborhood that was mostly middle-income Euro-American. She identified her college friends as a mixture of Hispanic, Middle Eastern and Euro-American peoples. Anna self-identified as a bilingual, Hispanic/Latina female who grew up in an urban neighborhood with a mostly lower-income, Hispanic population. Anna reported that she had no exposure to Asian, Native American, or Euro-American communities until she attended college. Clara also self-identified as a bilingual, Hispanic female, and reported growing up in a middleand lower-income rural neighborhood with a predominantly Hispanic population. Although she attended college with ethnically diverse students, her circle of friends remained Hispanic. Lisa identified as a Caucasian female, who grew up and continued to live in suburban communities of mostly middle-income Euro-Americans. She also grew up, and continued to socialize, with predominantly Euro-American friends while in college. Gabrielle identified as a Caucasian female, who grew up in a suburban, mostly middle-income, Euro-American neighborhood. During high school and college, she had a mixture of Asian American, African American, Hispanic, American Indian and Euro-American friends. 


\section{Professional Development for Supervisors}

Because CLRP and critical reflection were new components added to the supervision process, two professional development sessions were held for participating supervisors to provide the foundation for adoption of a culturally/linguistically responsive framework into the practice of supervision. During the first orientation at the beginning of the semester, supervisors participated in a half-day workshop, the purpose of which was threefold: (a) to review changes in supervisory duties for the semester, (b) to provide a new framework for CLRP supervision, and (c) to introduce a new observation guide. Training focused on the principles of CLRP and the CEC's (2009) knowledge and skill standards for multicultural competence in special education. The new observation guide developed for this study provided a framework to focus observations on the delivery of CLRP, an expectation of the Intercultural Communication and Collaboration course. It contained statements of criteria that should be observed at each stage of a lesson (e.g., students' current level of knowledge about topic is ascertained), as well as prompts that could be used during the follow-up conference (e.g., is instruction linked to students' background knowledge?). Prompts included general questions for each lesson stage as well as questions to scaffold a sociocultural perspective during debriefings.

During the mid-semester supervisor training, case studies of classroom teacher observations were presented and supervisors were asked to actively apply the supervisory observation guide to the cases. Following this session, the guide was reviewed and revised; specifically, questions addressing deeper layers of culture were added (e.g., are materials reflective of cultures/ethnicities/gender/religion/lived experiences of students in the classroom?). The revised guide was used for the observations conducted during the Total Teach period when STs assumed complete responsibility for their assigned classroom.

\section{Data Sources}

Audiotapes of the three final conferences between each supervisory-student teacher pair constituted the primary data source for the findings reported in this article. In total, 14 conversations ranging between 4 and 15 minutes were recorded and uploaded to a secure server during the Total Teach period. Lesson data files were created for each observation, consisting of the ST's lesson plan, the supervisor's observation form, as well as the transcripts of the audio recording. These files served to contextualize the supervision conference. For example, a section of the required lesson plan entitled "Cultural and Linguistic Diversity Considerations" prompted the students to actively consider how they would ensure CLRP in their instructional delivery and provided insight into their intentions. Towards the end of the data collection phase, one semistructured interview was conducted with each supervisor to ask questions about their philosophy about supervision, their expectations of student teachers, to obtain clarification of the transcripts, and to elicit supervisors' perceptions of the supervisory conference guide. All data were gathered by the first author. 


\section{Data Analysis}

Three types of analysis were used in the broader study (content analysis, and discourse analysis [interactional sociolinguistics and pragmatics]). Due to space limitations, we focus here on the content analysis of conversations about CLRP topics and the analysis of levels of reflection (interactional sociolinguistics).

Analysis of content of post-observation conversations. Two rounds of content analysis were conducted for each transcript: The first round of coding captured any topic that was initiated by both primary and secondary participants (e.g. assessment). In the second round, a system of external and internal coding (Graue \& Walsh, 1988) was used. External codes from culturally responsive education/special education frameworks in the literature were used to code CLRP strategies and other topics under the CLRP construct. Internal codes were created to capture topics not addressed by the external codes. For example, "repeated exposure to vocabulary terms" was assigned the code 'Linguistically Responsive Strategy (LRS) - pre-teaching vocabulary' (when vocabulary instruction occurred at the beginning of the lesson).

Analysis of the nature of the discourse. Discourse analysis was used to determine levels of reflection engaged in by STs (Hatton \& Smith, 1995). The analysis of speech acts (Austin, 1962) uncovered which participants engaged in reflection (Hatton \& Smith, 1995), how these topics emerged in conversations, and the effect of supervisor and ST statements on each other.

\section{Trustworthiness and Credibility}

Four methods were used to ensure trustworthiness and credibility - triangulation, member checking, declaring positionality, and audit trail. Multiple sources of data and multiple methods were used to confirm emerging findings (Merriam, 2009); specifically, content and discourse analysis were used to examine transcripts of supervisory conversations. Data from STs' lesson plans provided contextual information for topics that emerged in the supervisory conversations as did details from the content analysis of supervisors' semi-structured interviews. Triangulation of transcripts, lesson plans, observation notes, and semi-structured interviews helped ensure the validity of emergent themes. Member checking was used: (a) to provide clarity or more extensive information about the content (e.g., during the semi-structured interviews, segments of postobservation conference transcripts were presented to the participant supervisors); (b) to ensure accuracy of details (supervisor profiles were created and reviewed by the supervisors); and (c) to ascertain if the working hypotheses resonated with supervisors (feedback was elicited from them). Although the first author was also employed as a supervisor during this process, she did not supervise any STs. She maintained a professional relationship with all participants throughout the research process. A reflexive journal was also used throughout the data analysis process in order to limit any bias in the analysis and to provide an audit trail. 


\section{Findings}

The content and discourse analysis of supervisor/ST pairs revealed that CLRP topics were discussed, but the extent to which these conversations developed varied considerably. Speech acts (Austin, 1962) that emerged from the analysis included generating ideas, asking questions (STs), praising, informing, and evaluating (supervisors). Detailed descriptions of these conversations are followed by the emerging themes they revealed. Due to space limitations, repetitions, affirmative interjections by both STs and supervisors (e.g., that's right, uh huh) have been eliminated from the transcripts cited below.

\section{Quality of Student Teacher Reflection}

Discourse analysis using Hatton and Smith's (1995) framework revealed three levels of reflection (i.e., technical, descriptive and dialogic) in supervisor/ST conversations.

Descriptive reflection. When responding to Michelle's open-ended questions or prompts, Stephanie not only provided factual information (technical reflection) but also consistently evaluated the impact of her instruction or behavior management strategy on students (descriptive reflection). In the excerpt below, she describes her students making a cow puppet:

Stephanie: It was just a lot of...identifying the cow parts, and then gluing them on...I had my model paper bag cow open, so they could see how it would work as a puppet...That got them really excited, 'cause they...saw me moving it, and they were like "Oh cool!"

Michelle: (giggle). Yeah, that was one thing I really noticed, that you did a really nice job on, was having that model there with the students.

Stephanie engaged in descriptive reflection when concluding that her model of the puppet served to attract the students' attention and interest. She seemed to know that having a model ready would be effective, and through her reflection, concluded that it had the intended impact.

Near the end of her student teaching, Edwin asked Gabrielle to explain the beginning of class. She described her annoyance with two students who were particularly "non-compliant."

Gabrielle: His energy level was a little off the charts and he would be able to get down from the trampoline and get that out and I'd be fine, but... he wasn't even giving me a chance to give him that opportunity, I mean, I was asking... him to stop moving his body...just to be quiet for a minute, and that couldn't happen so, at that point, I gave him a strike, and I said three strikes you're out and that was the end of break...but we started out with our social rule and the social rule was based upon... one of the student's behavior this morning, about drawing things when he...wasn't supposed to be drawing like he's supposed to draw a simple horse, but he's got this obsession with Neanderthals and so he drew a Neanderthal horse and this...battle scene... and this has happened a lot, like this is not the first occasion. And so I figured that would be a good social rule... because it was about following 
directions when a teacher talks to us, why that's important and so that's what was going on (giggle), with the high energy level.

Gabrielle explained why she decided to give a student a strike for his misbehavior, and then evaluated the impact of how her decision to teach a social rule based on a behavior displayed by a student that morning tied in to her lesson about following teachers' directions. Throughout this exchange, she justified her actions and decisions, also demonstrating descriptive reflection.

Dialogic reflection. Dialogic reflection was demonstrated when Missy noticed that Clara did not provide students with opportunities to answer questions, as they had run out of time:

Missy: Why do you think that was, that you didn't have a whole lot of time?

Clara: We were trying to...fit in that extra read aloud... and we wanted to get to do some table work so...that's why I kind of felt like let me get extra done and then go into table work...and fit it all within the next...20 minutes...I probably should have just... asked for the questions, and then just...drop the whole table... at the end... and just let them have time for the questions, since we had said that we were going to do that earlier.

As she reflected, Clara arrived at the realization that there had not been enough time for both activities and concluded with a judgment about her own lesson (evaluating impact - negative).

In addition to reflecting on alternatives (dialogic reflection) when they realized that a strategy they used did not have the intended outcome, STs also reflected on alternatives on occasions when supervisors asked them what they might do differently. Lisa provided several reasons for choosing to sit next to the student instead of across from him.

Edwin: Earlier I saw examples of power-distance kind of play out in your lessons even just with it being one student...and, if you could walk me through what you thought about that, what that looked like to you.

Lisa: When it's just me and one student, I, I just find that I feel uncomfortable sitting across the table, and I know that that it's very much me versus you, it's kind of a face-off...That's what it feels like so, I decided I wanted to sit next to him, plus we were kind of sharing materials, it was a little less formal.

Edwin: Let's use...a [Intercultural Communication and Collaboration] term, and let's...think about power distance...Do you remember what conceptually that...talks about?

Lisa: Yeah!...The authority...a larger power distance would be...me sitting across the table, being very... much the teacher and he's very much the student. We have...our roles... and be very formal, but...especially with this one student, like, I...don't find that I need to...do as much behavior...because his attention is pretty much on me, 'cause I'm right there with him I feel like he's more comfortable with me sitting next to him. 
When asked about power distance, Lisa initially described her personal preference of sitting next to the student. Although she is aware that an alternative exists (descriptive reflection), she preferred to create an informal atmosphere. Later, though the topic of conversation had shifted briefly, Edwin chose to return to power distance, asking Lisa to think about power distance conceptually, and apply it to her lesson. First, Lisa stated her knowledge of the concept. She thought aloud through the alternative option of sitting across from the student, creating a formal teacher-student dynamic. She then stated reasons why she thought her choice was better. By focusing the conversation on the concept of power distance, Edwin prompted Lisa to engage in dialogic reflection by applying relevant theory to her analysis of her practice. Dialogic reflection also seemed to come into play when STs reflected on themselves critically.

Critical reflection of self. Jacobs (2006) identified critical reflection as an essential component of teaching for equity, and concluded that PSTs are typically able to reflect critically about their own disposition and practices before they are able to reflect critically on the injustices of school practices in relation to broader society. Each of these STs was able to be critical of their instruction, and to identify alternative methodologies. Critical self-reflection seems to be a subset of dialogic thinking; once aware of a negative impact of their instruction, STs explore alternative ways to improve their teaching. In response to a prompt from Missy:

Clara: I feel bad, but I should have publicly put more [emphasis] on the positive [behaviors] but I felt like there was a lot more, it was a lot of negative, but I probably should have addressed those positive [behaviors] like I did with that one student.

Critical self-reflection is clearly evident in this reflection, with Clara recognizing that she could improve her instruction by changing the nature of her reinforcement.

At their last conference, Michelle asked Anna what she would work on in the future:

Anna: Well, I guess...just I can always get better at incorporating, and making connections and using things that are valid for them...things that interest them. And I think, being able to incorporate things that would be important for them...

In another lesson, Edwin noted that he had seen Lisa teach the suffix -s, but wondered if she had taught the student the function of the suffix as a plural.

Lisa: I remember I did use the word plural because it was it was in the text, but I wasn't sure if he knew what I meant, so I kind of just said plural, and I was like...more than one (giggle), kind of being like I'm not sure if you know that word, so I'm just going to...give it to you. I should have probably asked him if he knew what it meant, but...

In this example, Lisa recognized that her instruction might have been more effective if she had clarified the student's understanding of the concept of plural. 


\section{Emerging Themes}

Further analysis of dialogues revealed two emerging themes: (a) Failed Attempts, and (b) Missed Opportunities. Failed Attempts are described as (seemingly) deliberate supervisor attempts to adopt a CLRP framework, only to have the direction of the conversation thwarted by the STs. Sometimes, supervisors initiated a conversation using a cultural lens or by addressing a topic related to CLRP; however, STs did not continue the conversation in this trajectory. Missed opportunities, on the other hand, are described as openings in conversations, where a supervisor could have used a comment made by a ST to generate CLRP related topics, but failed to do so.

Failed Attempts. Two conversations are illustrative of failed attempts. In an attempt to encourage Lisa to explore the topic from a cultural standpoint, Edwin brought up the term machismo in reference to a Hispanic male student who refused assistance. In a later interview, Edwin defined machismo as "culturally-informed pride in that which is masculine, and taking pride in that which is masculine." It was unclear whether Lisa understood this definition in the context of their conversation and rather than continuing the discussion, Lisa changed topics.

In her conference with Clara, Missy re-introduced a topic previously discussed about a young student who frequently took off her shoes at school. In that conversation, Clara had explained that the expectation at home was to take shoes off at the front door.

Missy: When we had a little discussion about cultural awareness... you had mentioned a particular student...taking off her shoes a lot. I'm wondering how that's going?

Clara: She's gotten a lot better. She actually did it earlier but it's because she had something in her shoe...she actually keeps them on and understands now that this is school and you need to keep them on and stuff so that's gotten a lot better.

Missy: Sure, and how did she come to that understanding? Was it conversation that someone had with her?

Clara: I know I haven't, and I don't know if my CT. I don't think we've had. I think she just kind of started to see maybe, just being in the classroom. And we always redirect her too: "you need to leave your shoes on when you're in school;" like I'll redirect her in that way, but not a set conversation, but just that redirection of... "leave your shoes on here in school" 'cause every time she'd take it off, they would make fun of [her].

Missy: Did you did you explain to her why? Or did anyone tell her why it's important to have her shoes on? The safety thing.

Clara: Now we're relating that to staying safe. Why you need to stay safe. This is why it's important and stuff like that...

Missy began the discussion with a direct reference to cultural awareness. However, Clara continued to raise the issue of behavior and the focus on CLRP was subverted. Eventually, Missy's focus also shifted to behavior, rather than maintaining the cultural lens she had been attempting to utilize. It appears that both of them needed more scaffolding for them to engage in this conversation from a sociocultural perspective. A culturally responsive teacher might explain to the student that there are sometimes differences between home norms and school norms, in this case, 
shoes are taken off at the door at home, but worn in school. This would have validated the practices of the home, yet provided the student with one of the repertoires of school practice (Seidl \& Pugach, 2009). Although Missy discovered that no one had addressed these issues with the student, she did not suggest or recommend that Clara should initiate this conversation.

Missed Opportunities. Missed opportunities occurred when supervisors had an opening to engage in a reflective conversation around culture, but did not. Michelle and Edwin each missed opportunities with two STs that could have been conversations about CLRP. In all cases, STs talked about a teaching strategy they claimed was culturally responsive and the supervisor accepted this at face value, rather than exploring how these strategies were responsive to culture.

In the prior example of a failed attempt, Lisa mentioned a student who isolated himself from a group of girls during math remediation by choosing to remain in the general education classroom. Although Edwin brought up the concept of machismo, the conversation followed a different track, and the student was not discussed further. However, it seemed that this student was not receiving the special education services to which he was entitled. Edwin missed this opportunity to engage Lisa in a conversation about the student's rights to services.

In attempting to facilitate Gabrielle's thinking about a topic external to the lesson he had observed, Edwin began by commenting on a note she had written in her lesson self-evaluation for the Intercultural Communication and Collaboration class. He noticed that she had expressed concern about a student whose family are members of the Jehovah's Witness denomination of Christianity. Gabrielle wrote that the student's family did not want him to establish friendships with students who were not Jehovah's Witnesses. When asked how she planned to address this, Gabrielle responded that she had already taught a social skills lesson focused on the idea that everyone can be friends, even if they have different opinions or beliefs.

Gabrielle: With him, if you directly talk about it...he is...die-hard Jehovah's Witness...he just talks about it you know, he wants to preach to his friends so that his friends can be Jehovah's Witnesses and they can be his real friend. So I'm just...trying to...keep it open that we can have true friends with different beliefs... without targeting...

Edwin: If I was in this situation, I was thinking maybe...even the difference between like a friend, and being friendly...Or like a friend, an acquaintance... Or a friend and a classmate...'cause the thing about it is that kind of gray area that maybe not be clear to a student with autism... also, looking at the message from home... a friend is just a member of this community, and you're not to have friends in the classroom or something like that or some way to kinda challenge that a little bit, with a way that also saves face, protects the integrity of the beliefs that they are getting from home too.

Gabrielle: And it's still reinforcing it. No...that would be a good talk, 'cause next year he's going to middle school. Not next year, it's like three months...and...just to build up like people who are your friends, and they can be there for you, and then people who are friendly to you, and acquaintances. I think that would be a good talk to have, 'cause I'm trying to think of everything I can to prepare him for this. 
Edwin clearly makes an effort to engage Gabrielle in a conversation about her concern. He provides a solution she can use at school and also brings up the cultural concept of "saving face, protecting the integrity of the beliefs they are getting from home." However, he misses an opportunity to converse with Gabrielle about ways to engage in cultural reciprocity (Kalyanpur \& Harry, 2012) with the parents of this student as well as the cooperating teacher. In schools, a typical goal for students with autism would be to teach strategies that increase socialization with peers. However, this would be difficult if the student's belief system is a mediating factor that affects with whom he can socialize. If the family and professionals were to discuss each other's goals in a safe and respectful way, there is a likelihood that common goals could be agreed upon.

Intersectionality of dialogic reflection with CLRP. Despite the failed attempts and missed opportunities, there were two dialogues in which STs engaged in dialogic reflection while simultaneously focusing on culturally and linguistically responsive practice.

For example, Gabrielle was explaining to Edwin the resources that students have at school to calm themselves down when they are agitated. The professor of the Intercultural Communication and Collaboration class had suggested that she help students identify resources at home that they could use to achieve the same effect, so that the learning at school could be generalized to their home settings. Edwin scaffolded Gabrielle's learning by talking about this topic using an equitable teaching lens. He explained that some students could probably afford to buy a tool they were using at school for their homes, but that might not be possible for others.

Edwin: But then the students that aren't able to afford that... what are they going to do when they get home? How can we make that more in parallel, so it doesn't put them at an unfair, you know, situation?

Gabrielle: So a good thing to do probably for that would be, just to really identify what that tool...how that tool, what that tool does, so if it's the tension, if it's the hugging of it all, you know, wrap up in a blanket, we can suggest things. They can still have those tools...if it's the fidgets...even with, one of our students it's the paper clips, you know.... and that's his fidget toy, and he pretends that it's (inaudible) and that gets him through the day and he'll pull it out during class and...you know, that's something that's going to internalize though...'cause it used to be a big fidget toy that he had with him ...

Edwin: Is that right?

Gabrielle: And now it's gone down to a small paper clip, so...we can think of other ways to get the same effect but just with different tools which they can find around their homes... Now I'm even thinking about tools they have at home, but...that they can make themselves...to give that same effect...And with these tools, we're really teaching them self-advocacy too because they're not going to work unless they're able to ask for 'em. That's a big thing with our students, like if we need a break, ask for it. Stand up for yourself, say, "this is what I need to be successful."

Gabrielle recognized that adapting instruction could go beyond school walls. Responding to Edwin's scaffolding about inequity, she generated an idea about students creating their own 
fidget tools so they could have parallel access to resources outside of school. She took up the conversation through this lens, and thought about ways to minimize the inequity, by exploring an alternative solution.

\section{Discussion and Implications}

The purpose of this study was to explore how supervisory conversations promoted ST critical reflection about CLRP. The findings revealed that (a) student teachers were successful in engaging in descriptive and dialogic reflection, and in critical self-reflection; (b) student teachers did not engage in critical reflection about institutional practices and systemic bias in special education; and (c) supervisors needed more experience and knowledge to engage STs in dialogue focused on culturally and linguistically responsive special education.

\section{Levels of Reflection Evident in Conversations}

Prompted by supervisor inquiry, STs were able to identify best practices in culturally and linguistically responsive pedagogy and generate ideas for incorporating CLRP to meet the needs of their diverse learners. STs were also able to critically reflect on themselves as practitioners; this aligns with a definition of critical reflection related to constructive self-criticism of one's actions with a view to improvement and transformation of one's own practice (Bates et al., 2009; CochranSmith et al., 2004; Larrivee, 2000).

The work in which students and supervisors are expected to engage should be a reflection of the philosophy of the teacher education program in which they are involved. The special education undergraduate program in which PSTs were enrolled shares characteristics that are similar to those of an inquiry-oriented program described by Zeichner and Liston (1985), which places "an explicit emphasis on encouraging students to reflect about the purpose and consequences of their classroom practice and about the classroom, school and community contexts in which they work" (p. 157). An emphasis on self-reflection and CLRP was infused throughout the program, including a focus on case studies of two children from different sociocultural and linguistic communities, during student teaching. Thus, by the time they are in their student teaching semester, STs have been provided with many opportunities for reflection over a period of two years, and at times with a particular focus on learners from CLD communities. However, the emphasis is on self-reflection and the impact of their teaching practices rather than critical reflection of pedagogy as a whole. The STs in this study applied self-reflection throughout their student teaching practice, suggesting that they had successfully acquired this skill.

\section{Failure to Engage in Critical Reflection About Institutional Practices}

No ST demonstrated critical reflection about institutional practices and their implications for society. This is consistent with the findings of other researchers who have studied PSTs and teacher education programs (Hatton \& Smith, 1995; Zeichner \& Liston, 1985). In her review of literature about supervision for equity, Jacobs (2006) concluded that PSTs would perhaps be able to develop critical reflection of themselves first, before reflecting broadly about practices at 
schools and their implications on society. In order to cultivate this type of critical reflection, however, PSTs need to demonstrate cultural self-awareness as related to teaching diverse others (Abt-Perkins et al., 2000). Howard (2003) contends that PSTs may find it difficult to examine their own biases, and thus guidance is needed from more experienced others. Although discussions and simulations were presented in coursework to facilitate PSTs in acknowledging their biases, these discussions were also conducted early in their teaching career, and perhaps need to be revisited or addressed more frequently through classes and coursework.

Hatton and Smith (1995) recommended that students should also be exposed to the literature of critical reflection to understand its nature. Hence, the absence of critical reflection in this data set may indicate a curricular gap rather than students' limited ability to reflect at this level. Despite the focus on CLRP, the focus on critical reflection may not have been explicit enough. Thus, it is suggested that pre-service teacher education programs should focus not only on self-reflection as a view to improving practices, but on reflection of the special education system as a whole, with a view to improving institutional and systemic bias.

The philosophy of a teacher education program is closely linked to the "beliefs and assumptions about the nature and purposes of schooling, teaching, teachers, and their education gives shape or form to specific forms of practice in teacher education" (Zeichner, 1983, p. 3). Zeichner noted that, in the social reconstructionist tradition of teacher education, the objective of teachers is to "work at changing their own practices because schools continue to reproduce a society based on unjust class, race and gender relationships" (as cited in Hatton \& Smith, 1995, p. 37). Perhaps a teacher education program that articulated the tenets of a social reconstructionist tradition through its curriculum, field placements, and supervision would be more successful at fostering a critical orientation in STs.

\section{Supervisors' Limited Experience and Knowledge About CLRP}

These findings showed that supervisors were not adequately prepared to engage their STs in dialogue in exploring the cultural dimensions of teaching and learning in depth and failed to model critical reflection themselves focused on CLRP (Abt-Perkins et al., 2000). The results of this study suggest however, that in some cases, STs may have had more knowledge about CLRP than their supervisors. For example, Anna's comments about centering curriculum on students' interests are concepts (i.e., personalization, self-determination) she would been exposed to in her curriculum. It is possible that her supervisor did not have exposure to these concepts, thus resulting in the missed opportunity to further develop this discussion.

Supervisors began the semester in which this study took place with variable levels of knowledge, skills, and experience with regard to supervision in general and to supervision for CLRP. The supervisor who was himself enrolled in a PhD program focusing on multiculturalism was the only supervisor who had dialogue that was sustained along a cultural trajectory. His knowledge of concepts such as power distance and equitable resources seemed to allow him to enter and refocus conversations along cultural lines. It is possible that in conversations characterized by missed opportunities and failed attempts, a supervisor more knowledgeable about cultural concepts might have been able to refocus or reframe the conversations with their STs. It 
is also interesting to note, however, that even someone with the level of knowledge that Edwin had from his post-graduate coursework also missed some opportunities that presented themselves during supervisory conferences. This suggests that knowledge about cultural and linguistic responsiveness may not be sufficient and that skills in supervisory techniques are also necessary for effective supervision.

All the supervisors in this study had some prior experience with supervising PSTs. However, the training received for supervision was limited. Supervisors were selected based on availability, interest and prior teaching experience. Prior to undertaking supervisory duties, supervisors needed to complete a three-hour online training module provided by the university, related to basic coaching techniques. As Zahorik (1988) noted, observation instruments do little to reduce supervisor variability. Practically, each supervisor underwent the same training on how to use the researcher-developed observation tool at the beginning and middle of the semester. However, supervision of the supervisors was not provided. Perhaps ongoing professional development of the supervisors vis-à-vis supervision skills, fostering critical reflection as well as individualized coaching with using the observation tool and would be necessary to develop supervisor capacity and efficacy aligned with the goals of the teacher education program.

\section{Limitations}

This study was exploratory and thus reflects the boundaries of such research. It is reflective of a single preparation program supported by external funding and transferability is limited by the duration, context, and number of participants. However, efforts have been made to provide rich descriptive detail so that readers can evaluate the transferability to their own contexts.

While beyond the scope of this study, it would be helpful to thoroughly analyze the undergraduate curriculum to determine the extent of the emphasis on the development of critical reflection in the pre-service program. Further, supervisors were not provided ongoing professional development in supervision techniques, which likely resulted in varied supervision skills among the supervisors. Lastly, although efforts were undertaken to maintain a professional relationship between the primary researcher and the participants, a previous social and professional relationship did exist. This could have influenced participants to be either more or less forthcoming in their responses or hesitant to be critical of the research.

\section{Implications for Research and Practice}

Future research is needed to confirm or broaden the current findings. The study could be replicated with additional supervisor and ST participants over a longer period of time and could be conducted in universities with various models of pre-service teacher preparation to investigate the transferability of the results to different contexts. Research could also be carried out on the scope and sequence of pre-service teacher education programs to investigate the extent to which critical issues related to CLRP in special education are covered, and the extent to which the skills required for critical reflection are developed in the curricula.

It would be useful to investigate the effects of more intensive supervisor training and its impact on the conduct of supervision conferences. Such research could investigate the effects of 
regular supervisor debriefing seminars in building supervisor capacity. Supervisors could be better prepared to evaluate the CLRP responsiveness of PSTs lesson plans. Research could also be conducted with the observation tool to determine ways to enhance its effectiveness and prompts could be added to focus on critical reflection (e.g., including key words such as access, equity, power and privilege.)

Another area worthy of study is to explore key components of professional development that are typically accorded to university supervisors in special education programs. Perhaps the use of established coaching techniques such as cognitive coaching (Costa \& Garmston, 2002) or educative mentoring (Feinman-Nemser, 2001) could be studied to investigate their effectiveness on supervision for culturally responsive instruction and critical reflection.

The findings of this study also offer programmatic and practical implications. First, they suggest that, programmatically, students may need more guidance in order to effectively apply literature on critical issues such as equity and access for CLD populations in special education in their field-based practice. In addition, they also need to be exposed to the literature on critical reflection in its broader sense and more scaffolding to engage in critical reflection of schools and society. In relation to this, students also need to be given more guidance and opportunities to practice critical reflection in addition to critical self-reflection. The study suggests that supervisors also need to have exposure to this literature.

The findings also suggested that supervisors should be knowledgeable about culturally and linguistically responsive practices so that they can guide their mentees' knowledge and application in practice. Similarly, supervisors should be able to model critical reflection to the STs, and scaffold the STs' use of it. Clearly, supervisors needed additional training with the observation tool in order to use it more effectively. Additionally, supervisors could be informed about different levels of reflection and well as question types that may invite deeper thinking and reflexivity. Along with the above, it would seem to be beneficial if supervisors were also supervised, perhaps by university professors who are responsible for teaching these curricula to the pre-service teachers.

In conclusion, consistent with other literature, supervisors failed to support their STs to engage in critical reflection. However, the supervision process as designed for this study seemed to hold promise, suggesting that both supervisors and STs may need more time and support to develop the requisite skills.

\section{References}

Abt-Perkins, D., Hauschildt, P., \& Dale, H. (2000). Becoming multicultural supervisors: Lessons from a collaborative field study. Journal of Curriculum \& Supervision, 16(1), 28-47.

Achinstein, B., \& Barrett, A. (2004). (Re)Framing classroom contexts: How new teachers and mentors view diverse learners and challenges of practice. Teachers College Record, 106, 716-746.

Amanti, C. (2005). Beyond a beads and feathers approach. In N Gonzalez, L. C. Moll, \& C. Amanti (Eds.), Funds of knowledge: Theorizing practices in households, communities, and classrooms (pp. 131-141). New York, NY: Routledge. 
Austin, J. L. (1962). How to do things with words. London, UK: Oxford University Press.

Bates, A. J., Ramirez, L., \& Drits, D. (2009). Connecting university supervision and critical reflection: Mentoring and modeling. Teacher Educator, 44, 90-112.

Bean, T. W., \& Stevens, L.P. (2002). Scaffolding reflection for preservice and inservice teachers. Reflective Practice, 3, 205-218.

Chamberlin, C. R. (2000). Nonverbal behaviors and initial impressions of trustworthiness in teachersupervisor relationships. Communication Education, 49, 352-364.

Cloud, N. (2002). Culturally and linguistically responsive instructional planning. In A. J. Artiles \& A. Ortiz (Eds.), English language learners with special needs: Identification, assessment, and instruction (pp. 107-132). Washington, D.C.: Center for Applied Linguistics.

Cochran-Smith, M., Davis, D., \& Fries, K. (2004). Multicultural teacher education: Research, practice and policy. In J. A. Banks, \& C. A. McGee Banks (Eds.), Handbook of research on multicultural education (2nd ed.), (pp. 931-978). San Francisco, CA: John Wiley \& Sons.

Costa, A. L., \& Garmston, R. J. (2002). Cognitive coaching: A foundation for Renaissance Schools. Norwood, MA: Christopher-Gordon.

Council for Exceptional Children (CEC). (2009). What every special educator must know: The international standards for the preparation and licensure of special educators (6th ed.). Reston, VA: Council for Exceptional Children.

Cuenca, A. (2010). Care, thoughtfulness, and tact: a conceptual framework for university supervisors. Teaching Education, 21, 263-278.

Denzin, N. K., \& Lincoln, Y.S. (2005). The SAGE handbook of qualitative research (3rd ed.). Thousand Oaks, CA: SAGE.

Feinman-Nemser, S. (2001). Helping novices learn to teach: Lessons from an exemplary support teacher. Journal of Teacher Education, 52(1), 17-30.

García, S. B., \& Ortiz, A. A. (2008). A framework for culturally and linguistically responsive design of response to intervention models. Multiple Voices for Ethnically Diverse Exceptional Learners, 11(1), 24-41.

García, S. B., \& Ortiz, A. A. (2013). Intersectionality as a framework for transformative research in special education. Multiple Voices for Ethnically Diverse Exceptional Learners, 13(2) 32-47.

Gay, G. (2000). Culturally responsive teaching: Theory, research and practice. New York, NY: Teachers College Press.

Gay, G. (2002). Preparing for culturally responsive teaching. Journal of Teacher Education, 53, 106-116.

Goldhammer, R. (1969). Clinical Supervision. New York, NY: Holt, Rinehart and Winston.

Graue, M. E., \& Walsh, D. J. (1988). Studying children in context: Theories, methods and ethics. Thousand Oaks, CA: SAGE.

Harry, B., \& Klingner, J. (2014). Why are so many minority students in special education? Understanding race and disability in schools (2nd ed.). New York, NY: Teachers College Press.

Hassaram, B. (2013). Preparing special education student teachers for critical reflection and culturally and linguistically responsive practice through supervision. (Unpublished doctoral dissertation). The University of Texas at Austin, Austin, TX.

Hatton, N., \& Smith, D. (1995). Reflection in teacher education: Towards definition and implementation. Teaching and Teacher Education, 11(1), 33-49.

Holland, P. E. (1989). Stories of supervision: Tutorials in a transformative practice of supervision. Peabody Journal of Education, 66(3), 61-77.

Hoover, J. J., Klingner, J. K., Baca, L. M., \& Patton, J. M. (2008). Methods for teaching culturally and linguistically diverse exceptional learners. Upper Saddle River, NJ: Pearson. 
Howard, T. C. (2003). Culturally relevant pedagogy: Ingredients for critical teacher reflection. Theory Into Practice, 42, 195-202.

Jacobs, J. (2006). Supervision for social justice: Supporting critical reflection. Teacher Education Quarterly, 33(4), 23-39.

Kalyanpur, M., \& Harry, B. (2012). Cultural reciprocity in special education. Baltimore, MD, Brookes.

Kozleski, E. B., \& Waitoller, F. R. (2010). Teacher learning for inclusive education: Understanding teaching as a cultural and political practice. International Journal of Inclusive Education, 14(7), 655666.

Larrivee, B. (2000). Transforming teaching practice: Becoming a critically reflective teacher. Reflective Practice, 1(3), 293-307.

Linan-Thompson, S., \& Ortiz, A. A. (2009). Response to intervention and English-language learners: Instructional and assessment considerations. Seminars in Speech and Language, 30, 105-120.

Little, M. E., \& Robinson, S. M. (1997). Renovating and refurbishing the field experience structures for novice teachers. Journal of Learning Disabilities, 30(4), 433-441.

Marxen, C. E., \& Rudney, G. L. (1999). An urban field experience for rural preservice teachers: I'm not afraid--should I be? Teacher Education Quarterly, 26(1), 61-74.

Merriam, S. B. (2009). Qualitative case study research. Qualitative research: A guide to design and implementation. San Francisco, CA: Jossey-Bass.

Orosco, M. J., \& O'Connor, R. (2014). Culturally responsive instruction for English language learners with learning disabilities. Journal of Learning Disabilities 47(6), 515-531.

Prater, M. A., \& Devereaux, T. H. (2009). Culturally responsive training of teacher educators. Action in Teacher Education, 31(3), 19-27.

Richardson-Koehler, V. (1988). Barriers to the effective supervision of student teaching: A field study. Journal of Teacher Education, 39(2), 28-34.

Robertson, P. M., García, S. B., McFarland, L. A., \& Rieth, H. J. (2012). Preparing culturally and linguistically responsive special educators: It "does" take a village. Interdisciplinary Journal of Teaching and Learning, 2(3), 115-130.

Robertson, P. M., García, S. B., \& Rodríguez, H. M. (2016). Walking the talk: Collaborative preparation of bilingual and special educators to serve English learners who need academic or behavioral supports. Multiple Voices for Ethnically Diverse Exceptional Learners, 16(2), 3-21.

Schön, D. A. (1987). Educating the reflective practitioner. San Francisco, CA: Jossey-Bass.

Seidl, B. (2007). Working with communities to explore and personalize culturally relevant pedagogies: Push, double images, and raced talk. Journal of Teacher Education, 58, 168-183.

Seidl, B., \& Pugach, M. (2009). Support and teaching in the vulnerable moments: Preparing special educators for diversity. Multiple Voices for Ethnically Diverse Exceptional Learners 11(2), 57-75.

Sleeter, C. (2008). An invitation to support diverse students through teacher education. Journal of Teacher Education, 59, 212-219.

Sobel, D. M., Gutierrez, C., Zion, S., \& Blanchett, W. (2011). Deepening culturally responsive understandings within a teacher preparation program: It's a process. Teacher Development, 15, 435452.

Sparks-Langer, G. M. \& Colton, A. B. (1991). Synthesis of research on teachers' reflective thinking. Educational Leadership, 48(6), 37-44.

Valencia, R. R. (2010). Dismantling contemporary deficit thinking: Educational thought and practice. London, UK: Routledge.

Villegas, A. M., \& Lucas, T. (2002). Preparing culturally responsive teachers: Rethinking the curriculum. Journal of Teacher Education, 53(1), 20-32. 
Weshah, H. A. (2007). Training pre-service teacher education on reflective practice in Jordanian universities. European Journal of Scientific Research, 18, 306-331.

Zahorik, J. A. (1988). The observing-conferencing role of university supervisors. Journal of Teacher Education, 39(2), 9-16.

Zeichner, K. (1983). Alternative paradigms of teacher education. Journal of Teacher Education 34(3), 39.

Zeichner, K. (2005). Becoming a teacher educator: A personal perspective. Teaching and Teacher Education, 21, 117-124.

Zeichner, K., \& Liston, D. (1987). Teaching student teachers to reflect. Harvard Educational Review, 57(1), 23-49.

Zeichner, K. M., \& Liston, D. (1985). Varieties of discourse in supervisory conferences. Teaching and Teacher Education, 1, 155-174.

Zeichner, K. M., Liston, D. P., Mahlios, M., \& Gomez, M. (1988). The structure and goals of a student teaching program and the character and quality of supervisory discourse. Teaching and Teacher Education, 4, 349-362.

Zozakiewicz, C. (2010). Culturally responsible mentoring: Exploring the impact of an alternative approach for preparing student teachers for diversity. Teacher Educator, 45, 137-151. 